\title{
Deep freezing of sheep embryos
}

\author{
S. M. Willadsen, C. Polge, L. E. A. Rowson and R. M. Moor \\ A.R.C. Unit of Reproductive Physiology \& Biochemistry, Cambridge, U.K.*
}

\begin{abstract}
Summary. Sheep embryos, collected 1-8 days after oestrus, were placed in Dulbecco's phosphate-buffered saline medium (PBS). After treatment, the viability of the embryos was tested by temporary transfer to ligated rabbit oviducts. In Exp. 1, Days 5-8 embryos survived for at least $15 \mathrm{~min}$ at $0^{\circ} \mathrm{C}$ in the presence of $1.5 \mathrm{M}$-DMSO. In Exp. 2 , $12 / 14$ Days 5-8 embryos survived after being frozen in $1.5 \mathrm{M}-\mathrm{DMSO}$ at $0.3^{\circ} \mathrm{C} / \mathrm{min}$ to temperatures ranging between $-15^{\circ}$ and $-60^{\circ} \mathrm{C}$ and then thawed at $12^{\circ} \mathrm{C} / \mathrm{min}$. In Exp. 3, Days 5-8 embryos were frozen in $1.5 \mathrm{M}$-DMSO at $0 \cdot 3^{\circ} \mathrm{C} / \mathrm{min}$ to below $-65^{\circ} \mathrm{C}$ before being transferred to liquid nitrogen $\left(-196^{\circ} \mathrm{C}\right)$, and stored for $12 \mathrm{hr}$ to 1 month. The embryos were thawed at $3^{\circ} \mathrm{C} / \mathrm{min}, 12^{\circ} \mathrm{C} / \mathrm{min}$ or $360^{\circ} \mathrm{C} / \mathrm{min}$ and, after transfer to rabbit oviducts, $0 / 4,10 / 36$ and $1 / 4$, respectively, developed normally. The 11 embryos which were considered normal when recovered from the rabbit oviducts plus 1 slightly retarded embryo were transferred to 7 recipient ewes. Four ewes subsequently lambed, producing 5 lambs. In addition, 8 embryos were transferred to 4 ewes directly after thawing. Three of these ewes subsequently lambed, producing 3 lambs.
\end{abstract}

\section{Introduction}

The development of reliable methods for long-term preservation of embryos of the large domestic species would greatly facilitate a more widespread application of embryo transplantation in the breeding of farm animals. The survival and normal development of mouse embryos after freezing and storage in liquid nitrogen have been achieved by techniques involving treatment of the embryos with media containing dimethylsulphoxide (DMSO) or glycerol combined with relatively slow rates of freezing and thawing (Whittingham, Leibo \& Mazur, 1972; Wilmut, 1972). The results of these experiments suggested that similar methods might be applied successfully to embryos of other species. So far, however, the only farm animal in which some success has been reported is the cow, and the birth of one calf following transplantation of frozen and thawed embryos has been obtained (Wilmut \& Rowson, 1973). The aim of the present experiments was to examine the possibility of deep freezing sheep embryos.

\section{Materials and Methods}

Mature Welsh Mountain ewes were injected with 1000 i.u. PMSG (Folligon: Organon) on Day 13 of the oestrous cycle (onset of oestrus=Day 0 ), mated to fertile Welsh Mountain $\times$ Suffolk rams at oestrus, and embryos were collected 1-8 days later by the method of Hunter, Adams \& Rowson (1955). The medium used for flushing the embryos from the reproductive tracts and for all subsequent procedures was Dulbecco's phosphate-buffered saline (PBS), enriched with energy-yielding substances and bovine serum albumin (Whittingham, 1971). After collection, the embryos were kept in PBS at room temperature $\left(\sim 20^{\circ} \mathrm{C}\right)$ for up to $2 \mathrm{hr}$ before being used in one of three experiments.

Experiment 1. Embryos at various stages of development, 2-celled to morula, were cooled to $0^{\circ} \mathrm{C}$ and kept at this temperature for $15 \mathrm{~min}$ before being re-warmed to room temperature (Exp. 1A). In Exp. 1B, embryos at the 8 to 16-cell stage and morulae ( $\gtrsim 32$ cells) were kept for $15 \mathrm{~min}$ at $0^{\circ} \mathrm{C}$ in the presence of $1.5 \mathrm{~m}$-DMSO. The DMSO concentration was increased and reduced in $0.25 \mathrm{M}$ steps

* Postal address: Animal Research Station, 307 Huntingdon Road, Cambridge CB3 0JQ, U.K. 
at room temperature or at $0^{\circ} \mathrm{C}$. The embryos were kept for $5 \mathrm{~min}$ at each intermediate DMSO concentration.

Experiments 2 and 3. Embryos, from morulae to blastocysts devoid of the zona pellucida ( $\gtrsim 120$ cells), were frozen in 1.5 M-DMSO in PBS. After addition of DMSO at room temperature as described for Exp. 1B, the embryos were transferred to test-tubes $(0.6 \times 5.5 \mathrm{~cm})$ containing approximately $0.2 \mathrm{ml} 1.5 \mathrm{M}$-DMSO in PBS. Tubes containing 2-6 embryos were placed in an ice-water bath, and after 5-10 min at $0^{\circ} \mathrm{C}$ they were transferred to an unsilvered Dewar flask $(10 \cdot 0 \times 20 \cdot 0 \mathrm{~cm}) \mathrm{con}$ taining $400 \mathrm{ml}$ ethanol at $-6^{\circ}$ to $-7^{\circ} \mathrm{C}$. Crystallization of the medium was initiated 2 min later by introducing a tiny crystal of frozen medium into each tube. The Dewar flask was then placed in a liquid nitrogen container and the distance between the surface of the liquid nitrogen and the bottom of the flask adjusted to give a cooling rate of approximately $0 \cdot 3^{\circ} \mathrm{C} / \mathrm{min}$. The ethanol in the flask was kept constantly stirred, and the freezing rate was recorded.

In Exp. 2 the tubes were thawed at approximately $12^{\circ} \mathrm{C} / \mathrm{min}$ from $-15^{\circ},-25^{\circ},-45^{\circ}$ and $-60^{\circ} \mathrm{C}$.

In Exp. 3 the tubes were frozen to temperatures ranging between $-65^{\circ}$ and $-70^{\circ} \mathrm{C}$ or $-125^{\circ}$ and $-130^{\circ} \mathrm{C}$, before being plunged into liquid nitrogen $\left(-196^{\circ} \mathrm{C}\right)$. The embryos were thawed after periods ranging from $12 \mathrm{hr}$ to 1 month. An attempt was made to standardize thawing procedures in order to obtain thawing rates of $3^{\circ}, 12^{\circ}$ or $360^{\circ} \mathrm{C} / \mathrm{min}$. A thawing rate of approximately $3^{\circ} \mathrm{C} / \mathrm{min}$ between $-80^{\circ}$ and $-5^{\circ} \mathrm{C}$ was obtained by placing the test-tube in a glass beaker $(4.5 \times 5.5 \mathrm{~cm})$ containing $40 \mathrm{ml}$ ethanol at $-120^{\circ} \mathrm{C}$. This was allowed to re-warm in air at room temperature. A thawing rate of approximately $12^{\circ} \mathrm{C} / \mathrm{min}$ between $-80^{\circ} \mathrm{C}$ and $-5^{\circ} \mathrm{C}$ was obtained by placing the test-tube in a larger tube $(1.5 \times 12.5 \mathrm{~cm})$ which had been cooled in liquid nitrogen; this was also allowed to re-warm in air at room temperature. A thawing rate of approximately $360^{\circ} \mathrm{C} / \mathrm{min}$ between $-80^{\circ}$ and $-5^{\circ} \mathrm{C}$ was obtained by agitating the test-tube in water at $27^{\circ} \mathrm{C}$. The post-thawing treatment was identical in Exps 2 and 3. Immediately after thawing the tubes were re-warmed rapidly to room temperature. The DMSO concentration was reduced in $0.25 \mathrm{M}$ steps until the embryos were back in pure PBS. They were kept for $10 \mathrm{~min}$ at each intermediate DMSO concentration to allow the blastomeres to contract to approximately their initial volume.

In all experiments survival and viability of embryos with the zona pellucida still present (Days 1-7) were assessed after transfer to ligated rabbit oviducts (Adams, Moor \& Rowson, 1968). After 1 or 2 days in the rabbit oviduct the embryos were removed and examined as fresh specimens. Those considered to have normal morphology after storage in liquid nitrogen and culture in the rabbit oviduct were transferred to the uterus of recipient ewes which had exhibited oestrus 7 days previously. One or two embryos were transferred to each ewe. The remaining embryos were fixed in $25 \%$ acetoethanol, stained with $1 \%$ lacmoid in $45 \%$ acetic aid, and examined by phase-contrast microscopy. Viability of frozen-thawed blastocysts devoid of the zona pellucida (Days 7-8) was tested by transfer to recipient ewes on Day 7 of the oestrous cycle directly after removal of DMSO.

\section{Results}

\section{Experiment 1}

The majority (15/19) of the embryos cooled to $0^{\circ} \mathrm{C}$ in the absence of DMSO (Exp. 1A) underwent cleavage when transferred to the rabbit oviduct. However, cleavage was judged to be normal in only $1 / 12$ embryos cooled at the 2-4-celled stage. By contrast, normal cleavage occurred in 5/7 later stage embryos. Only $3 / 12$ and $0 / 4$ embryos at the 8-16-celled stages treated with DMSO at room temperature and $0^{\circ} \mathrm{C}$, respectively (Exp. 1B), developed normally whereas $6 / 6$ and $4 / 5$ morulae subjected to the same treatments subsequently developed normally.

\section{Experiment 2}

The results of freezing embryos to temperatures ranging between $-15^{\circ}$ and $-60^{\circ} \mathrm{C}$ are shown in Table 1. Most of the embryos (12/14) recovered from the rabbit oviducts had developed normally.

\section{Experiment 3}

The results of freezing embryos to $-196^{\circ} \mathrm{C}$ are summarized in Tables 2 and 3 . Of the 52 embryos with the zona pellucida still present that were frozen (Table 2), 11 were considered normal, 6 showed 

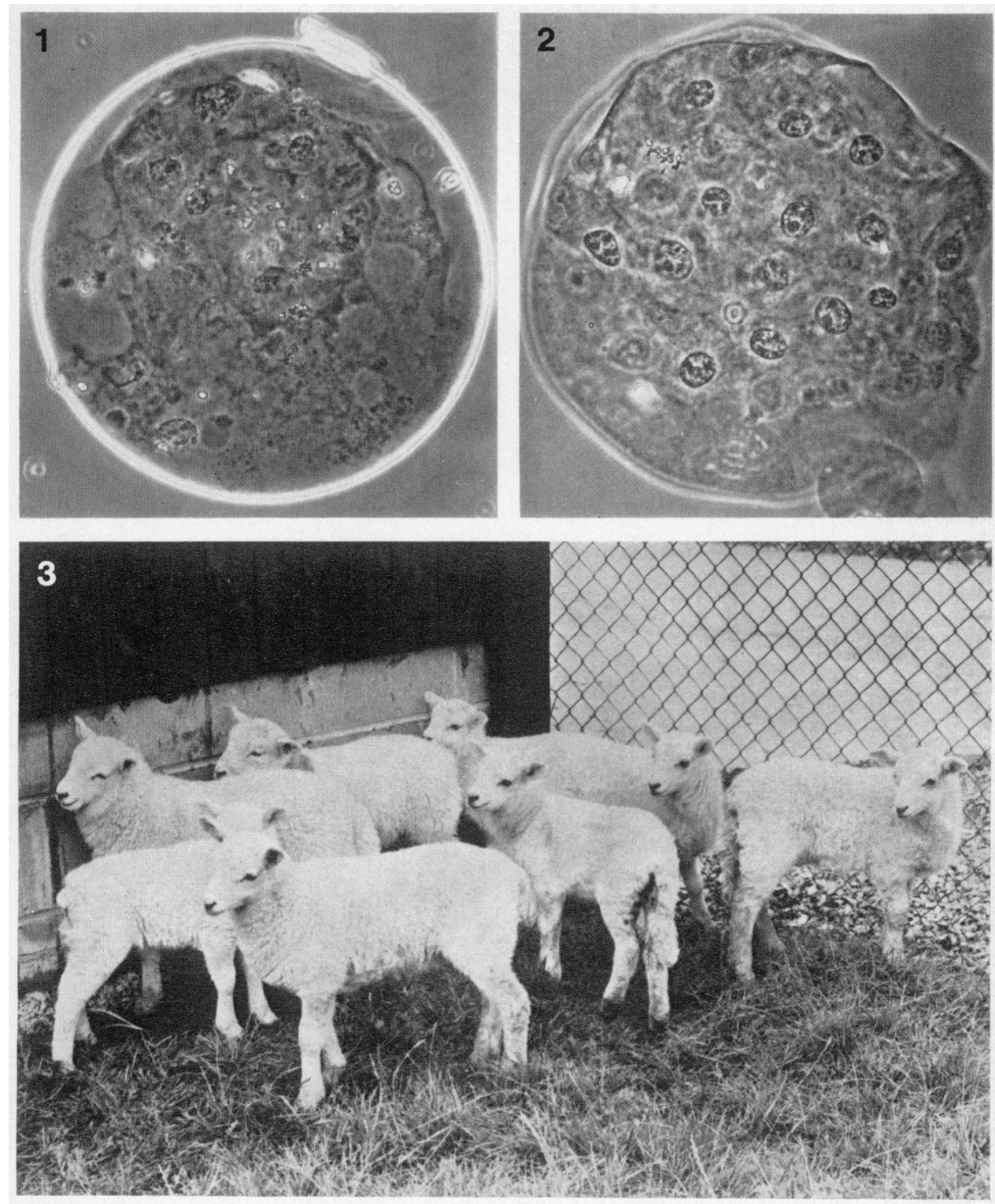

Fig. I. Sheep embryo fromen as a Da! 5 morula, showing degeneration after 2 dass in a ligated rabrit widuct. alehough a tew normal nuclei are still present. $\times 400$.

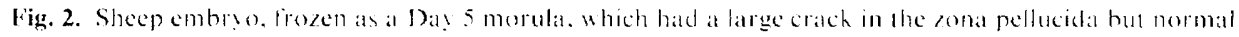
nuclear morphology. The embro was fixed after thawing and dilution of DMSO $x+(0)$.

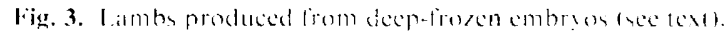


Table 1. Survival of sheep morulae and early blastocysts after freezing to various temperatures in the presence of $1.5 \mathrm{M}$-DMSO

\begin{tabular}{lcccc}
\hline & \multicolumn{3}{c}{ Freezing at $\sim 0.3^{\circ} \mathrm{C} / \mathrm{min}$ and thawing at } \\
\cline { 2 - 5 } \multicolumn{1}{c}{ Treatment } & $-15^{\circ} \mathrm{C}$ & $-25^{\circ} \mathrm{C}$ & $-45^{\circ} \mathrm{C}$ & $-60^{\circ} \mathrm{C}$ \\
\hline No. treated and transferred to rabbits & 5 & 4 & 4 & 4 \\
No. recovered from rabbits & 5 & 2 & 3 & 4 \\
No. showing continued development and normal morphology & 5 & 2 & 2 & 3 \\
\hline
\end{tabular}

Table 2. Survival of sheep morulae and early blastocysts frozen at $\sim 0 \cdot 3^{\circ} \mathrm{C} / \mathrm{min}$ in the presence of $1.5 \mathrm{M}$-DMSO and stored in liquid nitrogen

\begin{tabular}{lccc}
\hline \multicolumn{1}{c}{ Thawing rate } & $\sim 3^{\circ} \mathrm{C} / \mathrm{min}$ & $\sim 12^{\circ} \mathrm{C} / \mathrm{min}$ & $\sim 360^{\circ} \mathrm{C} / \mathrm{min}$ \\
\hline No. frozen & 5 & 43 & 4 \\
No. recovered after thawing & 5 & 42 & 4 \\
No. transferred to rabbits & 5 & 36 & 4 \\
No. recovered from rabbits & 4 & 35 & 4 \\
No. showing partial survival & 0 & 6 & 0 \\
No. considered normal & 0 & 10 & 1 \\
\hline
\end{tabular}

partial survival having $>20$ apparently normal blastomeres, and 26 having $<20$ normal blastomeres were considered degenerated (Pl. 1, Fig. 1). The 11 apparently normal embryos plus 1 slightly retarded embryo (thawed at $12^{\circ} \mathrm{C} / \mathrm{min}$ ) were re-transferred to 7 ewes, and 5 lambs were born (Table 3). A total of 10 blastocysts devoid of the zona pellucida was frozen. Upon thawing, 8 were recovered ( 6 thawed at $12^{\circ} \mathrm{C} / \mathrm{min}, 2$ at $360^{\circ} \mathrm{C} / \mathrm{min}$ ) and transferred directly to 4 recipient ewes; 3 lambs were born (Table 3).

Table 3. Transfer of sheep embryos frozen as morulae and early blastocysts (a) with the zona pellucida still present and retransferred after 1 day (Day 7 embryos) or 2 days (Day 5 and 6 embryos) in ligated rabbit oviducts, and (b) devoid of zona pellucida and transferred directly after thawing and dilution of DMSO

\begin{tabular}{cccc}
\hline & \multicolumn{3}{c}{ Embryos } \\
\cline { 2 - 3 } $\begin{array}{c}\text { No. of recipient } \\
\text { ewe }\end{array}$ & $\begin{array}{c}\text { No. } \\
\text { transferred }\end{array}$ & $\begin{array}{c}\text { Developmental } \\
\text { age (days) }\end{array}$ & $\begin{array}{c}\text { Lambs } \\
\text { born }\end{array}$ \\
\hline (a) $\quad 496$ & 2 & 6 & 0 \\
646 & $2 *$ & 5 & 0 \\
545 & 1 & 7 & 0 \\
616 & 1 & 7 & 1 \\
570 & 2 & 5 & 1 \\
632 & $2 \uparrow$ & 7 & 1 \\
568 & 2 & 6 & 2 \\
649 & 2 & 8 & 0 \\
587 & 2 & 7 & 1 \\
520 & 1 & 7 & 1 \\
& 1 & 8 & 1 \\
576 & $2 \ddagger$ & 8 &
\end{tabular}


To summarize, of the 8 embryos which developed to term (Pl. 1, Fig. 3), 1 had been frozen as a Day 5 morula, 2 as Day 6 morulae, 3 as Day 7 blastocysts, 1 as a Day 7 or Day 8 blastocyst, and 1 as a Day 8 blastocyst.

\section{Discussion}

The number of embryos used in these experiments was relatively small. Accordingly none of the results presented can be considered final or complete, but there can be no doubt that sheep morulae and early blastocysts can survive freezing to the temperature of liquid nitrogen, and develop into apparently normal lambs after thawing and transplantation.

The results of Exp. 1 suggest that the resistance of sheep embryos to cooling increases with age, and that treatment with DMSO has no harmful effect on the developmental potential of embryos which have reached the morula stage. However, in order to ensure a more complete penetration of the cryoprotectant into the embryos and reduce osmotic stress due to the relatively slow diffusion of DMSO at $0^{\circ} \mathrm{C}$, room temperature was chosen for DMSO treatment of embryos that were frozen.

In view of the results of Exps 1 and 2, it is unlikely that the pre-freezing and post-thawing treatments were responsible for the rather low survival rate obtained in Exp. 3. The failure of normal development was more likely to have been caused by damage occurring during freezing to and/or thawing from liquid nitrogen temperature. The DMSO concentration and freezing and thawing rates in these experiments were chosen on the basis of results reported on the deep-freezing of mouse embryos (Whittingham et al., 1972; Wilmut, 1972). For the mouse embryo the importance of relatively slow freezing and thawing rates, of the order of $0.2^{\circ}$ to $0.3^{\circ} \mathrm{C} / \mathrm{min}$ and $4^{\circ}$ to $25^{\circ} \mathrm{C} / \mathrm{min}$ respectively, has been stressed. A freezing rate of $0.3^{\circ} \mathrm{C} / \mathrm{min}$ and a thawing rate of $12^{\circ} \mathrm{C} / \mathrm{min}$ were employed in the majority of our experiments with sheep embryos, but survival was also obtained after a thawing rate of $360^{\circ} \mathrm{C} / \mathrm{min}$. Further experiments are needed to establish optimal conditions and the best stage for freezing sheep embryos. Some of the embryos frozen to $-196^{\circ} \mathrm{C}$ had cracks of various sizes in the zona pellucida after thawing. Cracks were not observed in embryos frozen to temperatures between $-15^{\circ}$ and $-60^{\circ} \mathrm{C}$, but they were more frequent in embryos which had been transferred to liquid nitrogen from $-65^{\circ}$ to $-70^{\circ} \mathrm{C}(12 / 32)$ than in embryos transferred to liquid nitrogen from $-125^{\circ}$ to $-130^{\circ} \mathrm{C}(1 / 19)$. In some instances large cracks occurred without visible damage to the blastomeres (Pl. 1, Fig. 2), and although such embryos were excluded from testing in the ligated rabbit oviduct, it is possible that they had survived freezing and thawing.

If deep-freezing of sheep embryos is to become a practical proposition, methods yielding substantially higher survival rates must be achieved. Judging from the results reported above this would appear to be possible.

We thank Professor T. R. R. Mann for reading the manuscript and acknowledge the valuable assistance of other members of the Unit staff. One of us (S. M. W.) gratefully acknowledges receipt of a Milk Marketing Board Research Fellowship.

\section{References}

Adams, C.E., Moor, R.M. \& Rowson, L.E.A. (1968) Survival of cow and sheep eggs in the rabbit oviduct. Proc. 6th Int. Congr. Anim. Reprod. \& A.I., Paris 1, 573-574.

Hunter, G.L., Adams, C.E. \& Rowson, L.E.A. (1955) Inter-breed ovum transfer in sheep. J. agric. Sci., Camb. 46, 143-149.

WhitTINGHAM, D.G. (1971) Survival of mouse embryos after freezing and thawing. Nature, Lond. 233, 125-126.
Whittingham, D.G., Leibo, S.P. \& MazUR, P. (1972) Survival of mouse embryos frozen to $-269^{\circ} \mathrm{C}$. Science, N.Y. 178, 411-414.

WiLMUT, I. (1972) Effect of cooling rate, warming rate, cryoprotective agent and stage of development on survival of mouse embryos during cooling and thawing. Life Sci. 11, 1071-1079.

Wilmut, I. \& Rowson, L.E.A. (1973) Experiments on the low-temperature preservation of cow embryos. Vet. Rec. 92, 686-690. 